\title{
Efeito de extratos de plantas medicinais no controle de Colletotrichum acutatum, agente causal da flor preta do morangueiro
}

\author{
Taís Ferreira Almeida, Margarete Camargo, Rita de C. Panizzi
}

Departamento de Fitossanidade, UNESP/FCAV, Jaboticabal, Via de acesso Prof. Paulo Donato Castellane s/n, CEP 14884-900. Parte da Dissertação de Mestrado do primeiro autor apresentada à UNESP/FCAV. Bolsista Capes.

Autor para correspondência: Taís F. de Almeida (taisfa@yahoo.com.br)

Data de chegada: 31/01/2005. Aceito para publicação: 03/07/2009

\section{RESUMO}

Almeida, T.F., Camargo, M., Panizzi, R.C. Efeito de extratos de plantas medicinais no controle de Colletotrichum acutatum, agente causal da flor preta do morangueiro. Summa Phytopathologica, v.35, n.3, p.196-201, 2009

A flor preta do morangueiro, causada por Colletotrichum acutatum, acarreta sérios problemas à cultura. Com o objetivo de verificar a utilização de extratos vegetais no controle da doença, testes "in vitro" foram realizados com 11 extratos vegetais hidroalcoólicos produzidos de plantas utilizadas na medicina popular. Os extratos foram preparados a partir de diferentes partes da planta, de acordo com a espécie, utilizando água e álcool no processo de extração por maceração.
Foi verificada a influência dos extratos no crescimento micelial, esporulação e germinação de esporos de C. acutatum, e também no controle do patógeno em folhas e frutos destacados. De acordo com a metodologia utilizada, os extratos vegetais que apresentaram maior eficiência foram os de folha e ramos de Ruta graveolens, Artemisia absinthium e bulbos de Allium sativum, indicando ter essas plantas potencial fungitóxico para o controle de C. acutatum.

Palavras-chave adicionais: controle biológico, Fragaria, planta medicinal.

\section{ABSTRACT}

Almeida, T.F., Camargo, M., Panizzi, R.C. Effect of plant extract on control of Colletotrichum acutatum the causal agent of the black spot of strawberry. Summa Phytopathologica, v.35, n.3, p.196-201, 2009

The black spot of strawberry plants caused by Colletotrichum acutatum, causes serious problems to the culture. To control the disease and minimize the use of fungicides, in vitro assays were accomplished with 11 different plant hydroalcoholic extract from plants species used in the popular medicine. The extracts were produced from plant parts (according to the species) using water and alcohol in the extraction process for infusion. The influence of the extracts was verified in the micelial growth, esporulation and germination of the pathogen, besides a test with leaves and outstanding fruits. In agreement with the methodology used in this study, the extracts that showed the highest efficiency were the ones from Ruta graveolens, Artemisia absinthium and Allium sativum, which indicate such plants as potential fungitoxics for the control of C. acutatum.

Keywords: biological control, Fragaria, medicinal plant.

A flor preta do morangueiro (Fragaria x ananassa Duch.), causada por Colletotrichum acutatum, ocasiona sérios problemas em todas as regiões de cultivo (18), podendo ser limitante para a cultura em virtude da sua natureza devastadora $(19 ; 23)$. É a doença de maior incidência nos cultivos de morangueiro no Brasil, causando danos durante todo o ciclo, com perdas de até $50 \%$ da produção (8).

Embora denominada flor preta, a doença manifesta-se em frutos de qualquer idade, pedúnculos, folhas, meristemas apicais e rizomas. As flores podem ser infectadas em qualquer época desde o inicio da formação de botões até seu completo desenvolvimento. Os frutos jovens quando afetados, também são necrosados e nem chegam a se formar. No campo, as lesões incidem em qualquer parte da superfície dos frutos e, sob condições de alta umidade, podem ser observadas massas rosadas de esporos do patógeno nas lesões $(25 ; 26)$.

De acordo com TANAKA et al. (25), a doença é de difícil controle, uma vez que as variedades em uso são muito suscetíveis e práticas culturais, tais como "mulching" e irrigação por aspersão, favorecem extremamente a doença. A utilização de fungicidas não tem apresentado um controle satisfatório, poucos são os produtos registrados para a cultura e, além disso, seu uso constante resultou no surgimento de formas resistentes do fungo $(25 ; 26)$. Além da falta de produtos registrados para cultura, outro fator limitante no controle de $C$. acutatum, refere-se ao custo, dificuldade no controle da doença durante o período de comercialização e segurança alimentar.

Como conseqüência, nota-se uma busca crescente por processos alternativos de controle de doenças economicamente viáveis. Produtos naturais incluindo compostos inorgânicos e uma variedade de extratos de plantas podem oferecer controle de doenças. De acordo com Jespers \& Waard (11), os extratos de plantas são conhecidos há séculos como medicinais e seu uso se estendeu a aplicações para o controle de pragas e doenças de plantas.

Algumas plantas são naturalmente resistentes a danos causados 
por patógenos, pois produzem compostos que são tóxicos ou que rompem o ciclo de vida desses organismos (3). Essas substâncias, denominadas compostos secundários ou aleloquímicos (28), são compostos biossinteticamente derivados de metabólitos primários e não têm função aparente, mas têm importante papel ecológico servindo, entre outros, como defesa química contra microrganismos, insetos e predadores (9). A maioria desses metabólitos pode ser obtida de parte de plantas através de destilação, extração com solventes ou aquosos (27), consistindo em técnicas com emprego de extratos vegetais, aminoácidos, microrganismos e óleos essenciais, enquadrandose em estratégias de controle alternativo de patógenos de plantas (8).

Nessa linha de pesquisa, visando explorar o potencial de compostos vegetais de plantas medicinais, o presente trabalho teve como objetivo avaliar o potencial, de substâncias obtidas de extratos das plantas medicinais Ruta graveolens, Zinziber officinales, Cymbopogon citratus, Catharanthus raseus, Artemisia absinthium, Nicotiana tabacum, Curcuma longa, Solidago chilensis, Azadirachta indica, Allium sativum e A. cepa, no controle de C. acutatum agente causal da flor preta do morangueiro e de patógenos de pós-colheita em frutos do morangueiro.

\section{MATERIAL E MÉTODOS}

Foram utilizadas onze plantas (Tabela 1) de diferentes espécies, para avaliar o efeito fungitóxico sobre $C$. acutatum, na cultura do morangueiro, cultivar IAC Campinas. O isolado utilizado de $C$. acutatum pertencente à Micoteca do Departamento de Fitossanidade FCAV/UNESP.

\section{Preparo dos extratos vegetais em meio BDA}

As amostras vegetais foram trituradas, na proporção de $20 \%$ $(\mathrm{p} / \mathrm{v})(60 \mathrm{~g}$ da amostra vegetal fresca/ $250 \mathrm{~mL}$ de água destilada esterelizada $+50 \mathrm{~mL}$ de álcool etílico hidratado $92,8^{\circ}$ ), e submetida ao processo de extração por maceração por um período de $48 \mathrm{~h}$. Posteriormente, os extratos foram filtrados em papel de filtro, esterilizados em membrana Millipore ${ }^{\circledR}$ $0,22 \mu \mathrm{m}$ e, armazenado em temperatura ambiente.

Os extratos vegetais esterilizados foram adicionados ao meio BDA (batata-destrose-ágar) na proporção de $20 \%$. A testemunha constituiuse do meio BDA acrescido de álcool etílico na concentração $20 \%$ e uma testemunha padrão, a qual utilizou BDA.
Efeito de extratos vegetais no desenvolvimento da colônia, esporulação e germinação de Colletotrichum acutatum

Discos de $5 \mathrm{~mm}$ de diâmetro foram retirados das colônias fúngicas de C. acutatum e transferidos para o centro de placas de Petri contendo o meio com os extratos vegetais. As placas foram incubadas em B.O.D. a $25 \pm 2{ }^{\circ} \mathrm{C}$ e fotoperíodo de $12 \mathrm{~h}$, por sete dias.

O tamanho das colônias fúngicas foi mensurado diariamente em duas posições perpendiculares entre si, durante sete dias, considerando-se o valor médio das medidas. O delineamento experimental empregado foi o inteiramente casualizado, com cinco repetições por tratamento, onde cada placa correspondeu a uma repetição.

Para avaliação de esporulação, discos de colônia de $5 \mathrm{~mm}$ de diâmetro foram retirados de toda extensão do raio da colônia fúngica, e transferidos para recipientes com $20 \mathrm{~mL}$ de água destilada com espalhante adesivo Tween 80 (uma gota em 100 $\mathrm{mL}$ de água). Estes foram agitados por $3 \mathrm{~min}$. A concentração de conídios foi determinada através de leitura em Câmara de Neubauer. Foram realizadas cinco repetição com três leituras cada, considerando-se o valor médio destas.

Para verificação da germinação de conídios, utilizou-se microplacas estéreis com 96 cavidades onde foram depositados $100 \mu \mathrm{L}$ de água esterilizada. Nestas colunas, foram acrescentados $20 \mu \mathrm{L}$ do extrato a ser testado, com exceção da coluna A (controle das amostras), que recebeu $20 \mu \mathrm{L}$ de água esterilizada. Foram adicionados posteriormente $80 \mu \mathrm{L}$ da suspensão, cuja concentração foi ajustada a $10^{4}$ conídios/ $\mathrm{mL}$. As placas foram mantidas a $25 \pm 2{ }^{\circ} \mathrm{C}$ por $24 \mathrm{~h}$. Foram avaliados 100 esporos/repetição, considerando germinados, os esporos que apresentavam tubo germinativo de comprimento igual ou superior aos dos conídios.

Utilizou-se o delineamento inteiramente casualizado. Os dados foram submetidos à análise de variância e as médias comparadas pelo teste de Tukey a $5 \%$ de probabilidade. Para efeito de análise estatística, as médias resultantes da avaliação de germinação foram transformadas em arco seno $(\mathrm{x} / 100)^{1 / 2}$.

Efeito de extratos vegetais no controle de Colletotrichum

Tabela 1 - Espécies vegetais e parte da planta utilizadas no preparo de extratos vegetais testados no controle in vitro de Colletotrichum acutatum.

\begin{tabular}{|c|c|c|c|}
\hline Espécies & Família botânica & Parte da planta utilizada & Compostos secundários* \\
\hline ArrudaRuta graveolens & Rutaceae & Parte aérea & Cumarina e alcalóides \\
\hline GengibreZingiber officinale & Zingiberaceae & Rizoma & Esquiterpenos \\
\hline Capim limãoCymbopogon citratus & Gramineae & Folhas frescas & Citral/ gerânio \\
\hline VincaCatharanthus roseus & Apocynaceae & Folhas e flores frescas & Alcalóides \\
\hline LosnaArtemisia absinthium & Compositae & Folhas e flores frescas & Carotenóides e flavonóides \\
\hline FumoNicotiana tabacum & Solanaceae & Folhas fresca & Alcalóides \\
\hline AçafrãoCurcuma longa & Zingiberaceae & Rizomas & Sesquiterpeno \\
\hline ArnicaSolidago chilensis M. & Compositae & Parte aérea & Flavonóides \\
\hline NimAzadirachta indica & Meliaceae & Ramos e folhas & Azadiractina \\
\hline AlhoAllium sativum & Liliaceae & Bulbos & Alicina ${ }^{1}$ \\
\hline CebolaAllium cepa & Liliaceae & Bulbos & Alicina \\
\hline
\end{tabular}

*Lorenzi, 2002; ${ }^{1}$ Leung, 1980. 


\section{acutatum em frutos destacados}

Frutos do morangueiro, em início de amadurecimento (cerca de $70 \%$ da superfície apresentando coloração rosada), foram desinfetados superficialmente com hipoclorito de sódio a 3\%, durante $1 \mathrm{~min}$. Posteriormente, foram imersos nos extratos vegetais na concentração de $20 \%$, por $3 \mathrm{~min}$, secos em ambiente sobre papel toalha por $2 \mathrm{~h}$ e colocados no interior de caixas tipo Gerbox, sendo que o controle foi imerso apenas em água. Em cada caixa foram colocados quatro frutos, eqüidistantes entre si, utilizando quatro caixas por tratamento.

A inoculação constituiu na deposição de discos de $5 \mu \mathrm{m}$ de diâmetro de colônias de C. acutatum, sobre os frutos de morangueiro. Os frutos foram mantidos em B.O.D. a $25 \pm 2{ }^{\circ} \mathrm{C}$ e fotoperíodo de 12 por $72 \mathrm{~h}$.

A avaliação consistiu na mensuração do tamanho da lesão em dois sentidos perpendiculares, considerando o valor médio. Adotouse o delineamento inteiramente casualizado com quatro repetições. As médias foram submetidas à análise de variância e comparadas pelo teste de Tukey a $5 \%$ de probabilidade.

Efeito de extratos vegetais no controle de patógenos em pós-colheita de frutos de morangueiro

Frutos do morangueiro foram coletados no comércio varejista de Jaboticabal/SP. Após desinfestação superficial conforme descrito no item anterior, os frutos foram imersos nos extratos vegetais na concentração de $20 \%$, por $3 \mathrm{~min}$, secos em temperatura ambiente e colocados em caixas tipo Gerbox. A testemunha constitui-se de frutos desinfestados superficialmente e frutos sem lavagem prévia, utilizados conforme são comercializados.

Em cada caixa foram colocados quatro frutos, eqüidistantes entre si, utilizando quatro caixas por tratamento. Os mesmos foram incubados em B.O.D a $27^{\circ} \mathrm{C}$ e fotoperíodo de $12 \mathrm{~h}$.

A avaliação foi realizada 96 h após a inoculação, onde se determinou os patógenos presentes nos frutos de morangueiro em pós-colheita. A incidência dos patógenos foi calculada através da fórmula: $\mathrm{I}=\left(\mathrm{n}^{\mathrm{o}}\right.$ de frutos infectados $/ \mathrm{n}^{\circ}$ total de frutos $) \times 100$.

Adotou-se o delineamento inteiramente casualizado com quatro repetições, sendo que cada repetição foi representada por uma caixa Gerbox com quatro frutos. Os resultados foram submetidos à análise de variância e as médias comparadas pelo teste de Tukey $5 \%$ de probabilidade.

Efeito dos extratos vegetais no controle de Colletotrichum acutatum em folhas destacadas de morangueiro

Folhas de morangueiro foram coletadas, lavadas e mantidas túrgidas mediante a justaposição de algodão umedecido acondionado no pecíolo.

Os extratos vegetais foram pulverizados nas folhas até o ponto de escorrimento. A inoculação foi realizada com uma borrifada $(0,15 \mu \mathrm{L})$ com suspensão ajustada na concentração de $10^{4}$ conídios/ $\mathrm{mL}$, sobre cada folíolo da folha. A testemunha recebeu somente água. Após a inoculação, as folhas permaneceram em câmara úmida por 15 dias.

A avaliação foi realizada diariamente, de acordo com a escala de severidade das lesões: $0=$ ausência de sintomas; $1=$ d" $25 \%$ de área com sintomas; $2=26-50 \%$ de área com sintomas; $3=51-$ $75 \%$ de área com sintomas; $4=76-100 \%$ de área com sintomas. Os resultados foram expressos em índice de doença através da fórmula: $\operatorname{ID}(\%)=\left(\mathrm{n}_{1} \mathrm{x} 0\right)+\left(\mathrm{n}_{2} \mathrm{x} 1\right)+\left(\mathrm{n}_{3} \mathrm{x} 2\right)+\left(\mathrm{n}_{4} \mathrm{x} 3\right)+\left(\mathrm{n}_{5} \mathrm{x} 4\right) \times 100 / 5 \mathrm{x}$ $\mathrm{N}$, onde: $\mathrm{IL}=$ índice de lesões, $\mathrm{n}_{1 \ldots 5}=\mathrm{n}^{\mathrm{o}}$ de folhas infectados (escala de notas) e $\mathrm{N}=\mathrm{n}^{\circ}$ total de folhas.

Utilizou-se o delineamento inteiramente casualizado com quatro repetições, sendo cada repetição representada por três folhas. Os dados obtidos foram submetidos a análise de variância e as médias comparadas pelo teste de Tukey a 5\% de probabilidade. Para efeito de análise estatística, as médias resultantes da avaliação fitopatológica foram transformadas em arco seno $(\mathrm{x} / 100)^{1 / 2}$.

\section{RESULTADOS E DISCUSSÃO}

De acordo com a análise de variância, observou-se que todos os extratos exerceram efeito inibitório no tamanho de colônia, esporulação e germinação de $C$. acutatum, diferindo estatisticamente $(P d$ " 0,01$)$ da testemunha (Tabela 2). Foi observado que o extrato de fumo foi o que exerceu melhor controle sobre o desenvolvimento micelial do patógeno, seguido do extrato de arruda e alho. Para a esporulação, os extratos de arruda e losna foram os mais eficientes. Os extratos de arruda, gengibre, vinca, losna, cebola, arnica e nim foram os que propiciaram melhor inibição da germinação dos conídios, estatisticamente diferindo da testemunha.

Os dados obtidos no presente trabalho assemelham-se aos citados por Oliva et al. (22) que trabalhando com arruda e losna, obtiveram resultados satisfatórios no controle de Botrytis cinerea, $C$. fragaria, C. gloeosporioides e Fusarium oxysporum. No entanto, Araújo et al. (2) em teste utilizando extratos vegetais de nim (A. indica), pimenta longa (Piper hispidinervium) e urtiga (Urtiga diocaica) verificaram que não houve efeito dos extratos vegetais no crescimento micelial de Alternaria porri e, uma redução significativa na esporulação nos tratamentos com urtiga e nim. De acordo com Miguel et al. (20) o óleo de Eucalyptus citriodora proporcionou redução no crescimento micelial de Colletotrichum spp. e Rhizopus spp., sendo a

Tabela 2 - Tamanho médio de colônia $(\mathrm{cm})$, esporulação e germinação de esporos de Colletotrichum acutatum em diferentes extratos vegetais, comparado ao meio de cultua padrão (BDA), após sete dias de incubação a $27{ }^{\circ} \mathrm{C}$ e fotoperíodo de $12 \mathrm{~h}$.

\begin{tabular}{lccc}
\hline Tratamentos & $\begin{array}{c}\text { Diâmetro médio } \\
\text { de colônia }(\mathbf{c m}) *\end{array}$ & $\begin{array}{c}\mathbf{N}^{\circ} \mathbf{d e}^{-1} \text { esporos. } \\
\mathbf{m L}^{-1}(\mathbf{1 0})^{* *}\end{array}$ & $\begin{array}{c}\text { Germinação* } \\
\mathbf{( \% )}\end{array}$ \\
\hline Fumo & $1,0 \mathrm{~h}$ & $43,3 \mathrm{c}$ & $20,5 \mathrm{bc}$ \\
Arruda & $1,6 \mathrm{gh}$ & $22,0 \mathrm{e}$ & $10,5 \mathrm{f}$ \\
Alho & $1,8 \mathrm{fg}$ & $29,0 \mathrm{de}$ & $21,0 \mathrm{~b}$ \\
Açafrão & $2,0 \mathrm{bcd}$ & $43,3 \mathrm{c}$ & $20,6 \mathrm{bc}$ \\
Vinca & $2,1 \mathrm{defg}$ & $34,3 \mathrm{~cd}$ & $12,3 \mathrm{ef}$ \\
Losna & $2,3 \mathrm{def}$ & $26,0 \mathrm{e}$ & $10,8 \mathrm{f}$ \\
Gengibre & $2,5 \mathrm{cde}$ & $40,3 \mathrm{c}$ & $11,7 \mathrm{ef}$ \\
Arnica & $2,6 \mathrm{~cd}$ & $76,0 \mathrm{~b}$ & $15,2 \mathrm{de}$ \\
Capim limão & $2,6 \mathrm{c}$ & $89,0 \mathrm{a}$ & $22,4 \mathrm{~b}$ \\
Cebola & $2,2 \mathrm{cdef}$ & $36,0 \mathrm{~cd}$ & $13,6 \mathrm{def}$ \\
Nim & $4,0 \mathrm{~b}$ & $71,0 \mathrm{~b}$ & $16,8 \mathrm{~cd}$ \\
BDA+extrator & $4,6 \mathrm{a}$ & $93,6 \mathrm{a}$ & $39,8 \mathrm{a}$ \\
Testemunha BDA & $4,8 \mathrm{a}$ & $96,3 \mathrm{a}$ & $43,6 \mathrm{a}$ \\
CV (\%) & 8,8 & 6,4 & 9,2 \\
DMS & 0,4 & 10,3 & 3,9 \\
\hline
\end{tabular}

* Médias de 5 repetições; ** médias de 3 repetições; ${ }^{1}$ Dados transformados em arco seno $(\mathrm{x} / 100)^{1 / 2} ;$ Médias seguidas da mesma letra, na coluna, não diferem entre si pelo teste de Tukey a $5 \%$. 


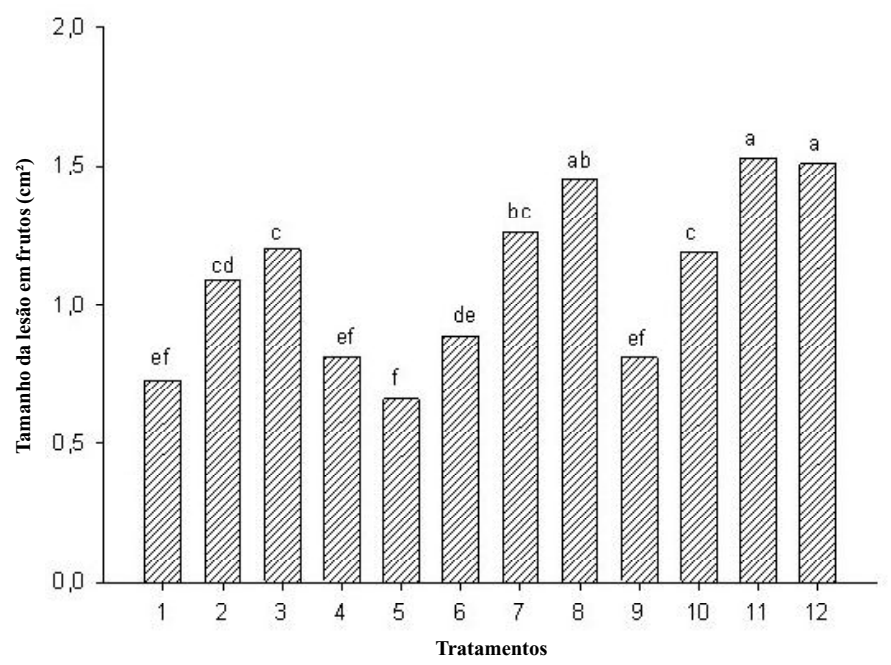

Tratamentos: 1 - Arruda; 2 - Gengibre; 3 - Capim limão; 4 - Vinca; 5 - Losna; 6 - Fumo; 7-Açafrão; 8-Arnica; 9 -Alho; 10 - Cebola; 11 -Nim; T1 - Testemunha com desinfestação; T2 - Testemunha sem desinfestação.

Figura 1. Efeito de extratos vegetais no desenvolvimento da lesão de Colletotrichum acutatum inoculado em frutos de morangueiro.

maior redução observada nas colônias de Rhizopus spp.. Leme et al. (13) observaram que extratos de primavera apresentaram eficiência semelhante ao óleo de nim no controle de C. acutatum.

O extrato de capim limão não apresentou resultado satisfatório em relação à produção de esporos, não diferindo estatisticamente da testemunha, contrariamente, os resultados obtidos por Lemos et al. (14) e Sridhar et al. (24) com o óleo de capim limão apresentou controle de C. lindemuthianum, Alternaria alternata, Aspergillus niger, A. flavus, Penicillium sp. e Rhizopus sp.. Embora Guirado et al. (9) não mencionem a forma de extração, estes autores citam o potencial das plantas Cymbopogon citratus, Allium sativum, Allium cepa, Azadirachta indica, Nicotiana tabacum entre outras, no controle de Rhizoctonia solani, Fusarium oxysporum, Pyricularia oryzae, Alterenaria tenuis, Botritis allii e outros patógenos de importância econômica

Em relação ao controle de C. acutatum em frutos de morangueiro (Figura 1) observou-se que todos os extratos exerceram efeito positivo na inibição do tamanho das lesões do patógeno sobre os frutos, sendo que os extratos de arnica e nim não diferiram estatisticamente da testemunha. O melhor desempenho foi observado com extrato de losna, arruda, vinca e alho.

Os patógenos identificados em pós colheita em morangos foram Rhizopus sp., Penicillium sp. e Botrytis sp.. Analisados isoladamente, os extratos não foram eficientes no controle de Botrytis sp. e Penicillium sp., havendo diferença significativa $\left(P d^{\prime \prime} 0,01\right)$ apenas para Rhizopus sp.. Os resultados de incidência de patógeno (Figura 2) revelaram que os extratos de losna e alho foram os únicos que apresentaram eficiência superior a $90 \%$. Os extratos de arruda, gengibre e fumo controlaram em $100 \%$ Rhizopus sp. e apenas o extrato de vinca apresentou controle sobre a incidência de Penicillium sp.. Dias-Arieira et al. (5) observaram que embora o óleo de nim tenha proporcionado controle no crescimento micelial de Rhizopus spp. não apresentou a mesma eficiência em frutos, sendo que, os morango tratados com o óleo de nim e inoculado com Rhizopus spp. após 48 horas apresentavam completo apodrecimento.

De acordo com os resultados referentes ao efeito dos extratos vegetais no controle de C. acutatum em folhas destacadas, observouse que houve maior eficiência do extrato de losna e arruda, diferindo estaticamente da testemunha. Os resultados indicaram que há uma maior eficiência da maioria dos extratos até 10 dias após o tratamento, notando-se que a partir deste período há um aumento no nível de severidade, independente dos tratamentos utilizado.

Não foi observado efeito de fitotoxidez em folha e frutos usados neste ensaio e em nenhum dos experimentos realizados.

De forma geral, concluímos que os extratos obtidos a partir de alho, arruda, fumo e losna foram os que apresentaram maior ação fungitóxica a $C$. acutatum, assim como para os patógenos de póscolheita, Botrytis sp., Penicillium sp. e Rhizopus sp. Isto sugere que os extratos podem ser usados como alternativa ao controle de $C$. acutatum integrando as técnicas de pós-colheita, com as práticas de campo, minimizando assim, a utilização de agrotóxicos.

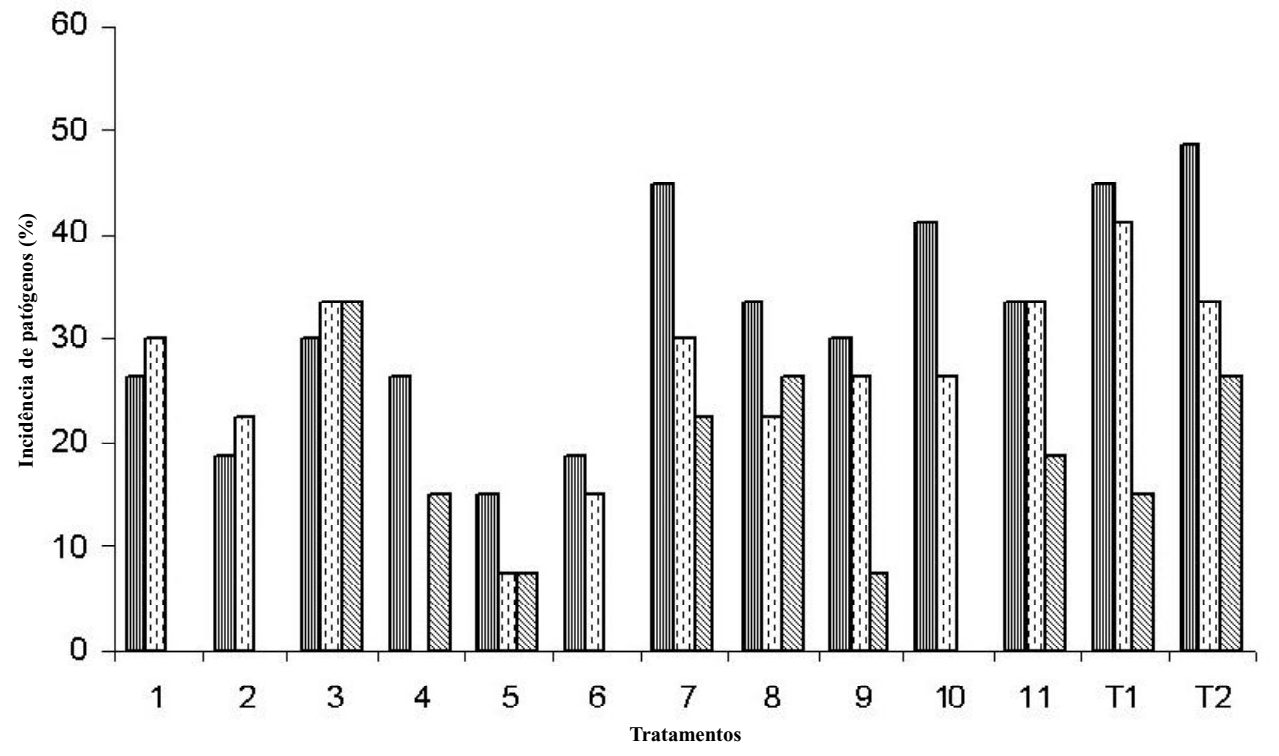

四Botrytis sp.

田Penicillium sp.

Rhizopus sp.
Tratamentos: 1 - Arruda; 2 - Gengibre; 3 Capim limão; 4 - Vinca; 5-Losna; 6 - Fumo; 7- Açafrão; 8-Arnica; 9-Alho; 10 -Cebola; 11 - Nim; T1 - Testemunha com desinfestação; T2 - Testemunha sem desinfestação.

Figura 2. Incidência (\%) de Botrytis sp., Penicillium sp. e Rhizopus sp. em frutos de morangueiro tratados com diferentes extratos vegetais. 
Tabela 3 - Efeito dos extratos vegetais no controle de Colletotrichum acutatum em frutos e folhas destacadas de morangueiro.

\begin{tabular}{|c|c|c|c|}
\hline \multirow{3}{*}{ Tratamentos } & \multicolumn{3}{|c|}{ Severidade das lesões em folhas de morangueiro $(\%)$} \\
\hline & \multicolumn{3}{|c|}{ Dias após a inoculação } \\
\hline & 5 dias & 10 dias & 15 dias \\
\hline Arruda (Ruta graveolens) & $7,89 \mathrm{~cd}$ & $10,15 \mathrm{~b}$ & $45,98 \mathrm{c}$ \\
\hline Jengibre (Zinziber officinale) & $10,96 \mathrm{abc}$ & 14,49 a & $60,10 \mathrm{ab}$ \\
\hline Capim limão (Cymbopogon citratus) & $10,28 \mathrm{abcd}$ & $14,50 \mathrm{a}$ & $53,36 \mathrm{bc}$ \\
\hline Vinca (Catharanthus roseus) & $11,75 \mathrm{ab}$ & $13,10 \mathrm{ab}$ & $51,75 \mathrm{bc}$ \\
\hline Losna (Artemisia absinthium) & $7,99 \mathrm{~cd}$ & $10,17 \mathrm{~b}$ & $46,21 \mathrm{c}$ \\
\hline Fumo (Nicotiana tabacum) & $7,15 \mathrm{~d}$ & $11,80 \mathrm{ab}$ & $47,82 \mathrm{c}$ \\
\hline Açafrão (Curcuma longa) & 9,86 abcd & $12,47 \mathrm{ab}$ & $52,67 \mathrm{bc}$ \\
\hline Arnica (Solidago chilensis) & $11,12 \mathrm{abc}$ & $12,13 \mathrm{ab}$ & $50,72 \mathrm{bc}$ \\
\hline Alho (Allium sativum) & 9,06 bcd & $11,30 \mathrm{ab}$ & $50,33 \mathrm{bc}$ \\
\hline Cebola (Allium серa) & $10,73 \mathrm{abc}$ & $12,35 \mathrm{ab}$ & $52,75 \mathrm{bc}$ \\
\hline Nim (Azadirachta indica) & 10,54 abcd & $13,02 \mathrm{ab}$ & $50,61 \mathrm{bc}$ \\
\hline Testemunha & $12,56 \mathrm{a}$ & $14,15 \mathrm{a}$ & $64,15 \mathrm{a}$ \\
\hline $\mathrm{F}$ & $5,34 * *$ & $2,81 *$ & $6,00^{*}$ \\
\hline C.V (\%) & 13,55 & 12,78 & 8,00 \\
\hline DMS & 3,36 & 3,95 & 10,30 \\
\hline
\end{tabular}

${ }^{1}$ Dados transformados em arco seno $(\mathrm{x} / 100)^{1 / 2}$. significativo, a $5 \%$ de probabilidade; $* *$ significativo, a $1 \%$ de probabilidade.

Médias seguidas da mesma letra, na coluna, não diferem entre si pelo teste de Tukey $5 \%$.

No caso específico da arruda, os dados apresentados assemelhamse com os resultados obtidos por Aliotta et al. (1) e Ojala et al. (21), os quais verificaram o potencial da arruda para controle dos patógenos Rhizoctonia solani, Fusarium spp., Pyrenochaeta lycopersici, Penicillium spp., Thielaviopsis basicola e Verticillium dahliae. Estes resultados são de grande validade prática, considerando que tal planta apresenta potencial no controle de patógenos de importância econômica, constituindo em uma alternativa promissora na agricultura orgânica.

A discrepância entre os resultados obtidos com extratos vegetais se justifica pela falta de padronização na metodologia de obtenção dos princípios ativos da planta, ou seja, na obtenção dos extratos vegetais assim como a forma de esterilização e armazenamento dos mesmos. Leme et al. (12) verificaram que a metodologia utilizada na esterilização e o tempo de estocagem do extrato vegetal de capim limão interferiram na atividade do mesmo em relação ao desenvolvimento micelial de Colletotrichum acutatum. Além dos fatores mencionados, outras características como época de coleta das plantas e tipo de solo de cultivo está diretamente relacionada com a concentração dos compostos ativos presente na planta.

Embora não se tenha resultados de controle de C. acutatum em campo utilizando os extratos vegetais, a eficiência destes não deve ser descartada, no entanto estudos devem ser realizados para utilização adequadas destes produtos.

\section{REFERÊNCIAS BIBLIOGRAFICAS}

1. Aliotta, G.; Caiero, G.; De Feo, V.; Di Blasio, B.; Iacovino, R.; Oliva, A. Allelochemicals from rue (Ruta graveolens L.) and olive (Olea europaea L.) oil mill waste waters as potential natural pesticides. Curr. Top. Phytochem, v.3, p.167-177, 2000.

2. Araújo, C.M.M.; Silva, A.M.; Bentes, J.L.S.; Bezerra, E.J.S.; Almeida, D.F.; Cruz, R.E.T. Efeito de diferentes extratos vegetais no crescimento micelial e produção de esporos de Alternaria porri. Fitopatologia Brasileira, Brasília, v. 31 (suplemento), p. S158, 2006.

3. Arnason, J.T.; Philogene, B.J.R.; Morandi, P. Inseticides of plant origin. Washington: The American Chemical Society, 1989. $213 \mathrm{p}$.

4. Coutinho, W.M.; Araújo, E.; Magalhães, F.H.L. Efeito de extratos de plantas anacardiáceas e dos fungicidas químicos benomyl e captan sobre a micoflora e qualidade fisiológica de sementes de feijoeiro (Phaseolus vulgaris L.). Ciência e Agrotecnologia, Lavras, v.23, p.560-568, 1999.

5. Dias-Arieira, C.R.; Toppa, E.V.B. Avaliação do óleo de nim (Azadirachta indica) no controle de Rhizopus spp. em morango. Fitopatologia Brasileira, Brasília, v. 31 (suplemento), p. S159, 2006 .

6. Domingues, R.L.; Tofoli, J.G.; Oliveira, S.H.F.; Garcia Júnior, O. Controle químico da flor preta (Colletotrichum acutatum) do morangueiro em condições de campo. Arquivo Instituto Biológico, Campinas, v.68, p.37-42, 2001.

7. Fortes, J.F.; Osório, V.A. Morango: fitossanidade. Embrapa Clima Temperado, Pelotas, RS, Informe tecnológico. 2003. 36p.

8. Franco, D.A.; Bettiol, W. Controle de Penicillium digitatum em pós-colheita de citros com produtos alternativos. Fitopatologia Brasileira, Brasília, v.25, p.602-606, 2000.

9. Guirado, N.; Ambrosano, E.J.; Mendes, P.C.D.; Rossi, F.; Arévalo, R.A. Controle de doenças em sistemas agroecológico. Summa Phytopathologica, Botucatu, v.30, n.1, p.153-156, 2004.

10. Harborne, J.B. Phytochemistry ecology . New York: Academic Press, 1972.

11. Jespers, A.B.K.; Waard, M.A.. Natural products in plant protection. Neth. Journal Plant Pathology, Wageningen, v.99, p.109$117,1993$.

12. Leme, M.I.S.; Camargo, M.; Furlani, A.C.F.A.; Panizzi, R.C.; Leite, R.F.; Rosa, J.. Efeito in vitro de capim limão no desenvolvimento micelial de Colletotrichum acutatum. Summa Phytopathologica, Botucatu, v. 33 (suplemento), p. S92, 2007.

13. Leme, M.I.S.; Camargo, M.; Furlani, A.C.F.A.; Panizzi, R.C.; Leite, R.F.; Rosa, J.. Efeito in vitro de extratos de nim e primavera no desenvolvimento micelial de Colletotrichum acutatum. Summa Phytopathologica, Botucatu, v. 33 (suplemento), p. 
S92, 2007.

14. Lemos, T.L.G.; Monte, F.J.Q.; Matos, F.J.A.; Alencar, J.W.; Craveiro, A.A. Chemical composition and antimicrobial activity of essential oils from brazilian plants. Fitoterapia, Milão, v.63, p.266-268, 1992.

15. Leung, A. Encyclopedia of common natural ingredients used in food, drugs and cosmetics., New York, John Willey, 1980. p. 176-178.

16. Lorenzi, H.; Matos, F.J.A. Plantas medicinais no Brasil: nativas e exóticas cultivadas. INova Odessa, SP. Instituto Plantarum, 2002. 512p.

17. Mass, J.L.; Palm, M.E. Occurrences of anthracnose irregular leafspot, caused by Colletotrichum acutatum, on strawberry in Maryland. Adv. Strawberry Res. v.16, p.68-70, 1979.

18. Mass, J.L. Compendium of strawberry diseases, $2^{\text {nd }}$ ed. St. Paul: American Phytopathological Society Press, 1998. 96p.

19. Mena, A.J.; De Garcia, E.P.; Gonzalez, M.A. Presencia de la antracnosis de la fruttila en la Republica Argentina. Revista Agronomica del Noroeste Argentino, v.11, p.307-312, 1974.

20. Miguel, E.G.; Ferreira, L.R.; Donega, M.A.; Dias-Arieira, C.R.. Atividade de óleo de Eucalyptus citricodora no crescimento de Colletotrichum spp. e Rhizopus spp. Fitopatologia Brasileira, Brasília, v. 31 (suplemento), p. S159, 2006.

21. Ojala, T.; Remes, S.; Haansuu, P.; Vuorela, H.; Hiltunen, R.; Haahtela, K.; Vuorela, P. Antimicrobial activity of some courmain containing herbal plants growing in Finland. Journal Ethnopharmacol v.73, p.299-305. 2000.

22. Oliva, A.; Meepagala, K.M.; Wedge, D.E.; Harries, D.; Hale, A.L.; Aliotta G.; Duke, S.O. Natural fungicides from Ruta graveolens L. leaves, including a new quinolone alkaloid. Journal of Agricultural and Food Chemistry, v.51, p.890-896, 2003.

23. Smith, B.J.; Black, L.L. Morphological, Cutural and Pathologenic variantion among Colletotrichum species isolated from strawberry. Plant Disease, St. Paul, v.74, p. 69-76, 1990.

24. Sridhar, S.R.; Rajagopal, R.V.; Rajavel, R.; Masilamani, S.; Narasimhan, S. Antifungal activity of some essencial oils. Journal of Agricultural and Food Chemistry, v.51, p.7596-7599, 2003.

25. Tanaka, M.A.S.; Betti, J.A.; Kimati, H. Doenças do morangueiro (Fragaria x ananassa Duch.). In: Kimati et al. (Ed.) Manual de fitopatologia: doenças das plantas cultivadas, 3. ed. São Paulo: Agronômica Ceres, 1997. v. 2, p. 556-571.

26. Tanaka, M.A.S.; Betti, J.A.; Kimati, H. Doenças do morangueiro (Fragaria x ananassa). In: Kimati et al. (Ed.) Manual de fitopatologia: doenças das plantas cultivadas, 4. ed. São Paulo: Agronômica Ceres, 2005. v. 2, p. 467- 474.

27. Tyler, V.E.; Brady, L.R.; Robbers, J.E. Pharmacognosy. 8 th ed. Philadelphia: Lea and Febiger, 1981.

28. Whittaker, R. H. The biochemical ecology of higher plants. In: Sondjeimer, E.; Simeone, J.B. (Ed.). Chemical ecology. New York: Academic Press, p.43-47. 1972. 